OPEN ACCESS

Edited by:

Giuliana Valerio,

Università Degli Studi Di Napoli

Parthenope, Italy

Reviewed by:

Hugo Fideleff,

Universidad De Buenos Aires,

Argentina

Alicia Belgorosky,

Garrahan Hospital, Argentina

*Correspondence:

Mauro Bozzola

mauro.bozzola@unipv.it

Specialty section:

This article was submitted to

Pediatric Endocrinology,

a section of the journal

Frontiers in Pediatrics

Received: 18 June 2018 Accepted: 19 October 2018 Published: 12 November 2018

Citation:

Pagani S, Bozzola E, Strisciuglio C, Meazza C, Miele E, Malamisura M, De Angelis P and Bozzola M (2018)

Growth Hormone Receptor Gene

Expression Increase Reflects Nutritional Status Improvement in

Patients Affected by Crohn's Disease.

Front. Pediatr. 6:338.

doi: 10.3389/fped.2018.00338

\section{Growth Hormone Receptor Gene Expression Increase Reflects Nutritional Status Improvement in Patients Affected by Crohn's Disease}

\author{
Sara Pagani ${ }^{1}$, Elena Bozzola ${ }^{2}$, Caterina Strisciuglio ${ }^{3}$, Cristina Meazza ${ }^{1}$, Erasmo Miele ${ }^{4}$, \\ M. Malamisura ${ }^{5}$, Paola De Angelis ${ }^{5}$ and Mauro Bozzola ${ }^{1 *}$ \\ 1 Unit of Pediatrics and Adolescentology, Department of Internal Medicine and Therapeutics, University of Pavia, Pavia, Italy, \\ ${ }_{2}^{2}$ Pediatrics Department Bambino Gesù Children's Hospital, Rome, Italy, ${ }^{3}$ Department of Women, Children and General and \\ Specialized Surgery, Second University of Naples, Naples, Italy, ${ }^{4}$ Pediatric Gastroenterology Division, University of Naples \\ Federico II, Naples, Italy, ${ }^{5}$ Digestive Surgery and Endoscopy Unit, Bambino Gesù Children's Hospital, Rome, Italy
}

Background: We proposed to verify the role of growth hormone receptor gene expression in growth failure of children with Crohn's disease (CD).

Methods: We measured serum levels of growth hormone binding protein (GHBP) and insulin-like growth factor-I (IGF-I), and growth hormone receptor (GHR) gene expression in peripheral blood mononuclear cells of 21 patients with CD (before and after therapy) and in 27 age-sex-matched controls.

Results: At diagnosis, significantly lower insulin-like growth factor-l and growth hormone binding protein levels were found in the CD group compared to the controls. Growth hormone receptor mRNA expression was lower in patients at diagnosis compared to the controls, even though the difference did not reach statistical significance, and significantly increased in patients in the following year. Insulin-like growth factor-l levels showed significant improvements 1 year after diagnosis compared to basal levels. On the contrary, growth hormone binding protein values had not significantly changed after 1 year of therapy.

Conclusion: Our study raises the hypothesis of another mechanism through which cytokines interact with the growth hormone/insulin-like growth factor-I (GH/IGF-I) axis.

Keywords: IGF-I, short stature, inflammation, GHBP, growth hormone receptor, Crohn's disease

\section{INTRODUCTION}

Crohn's disease (CD) is a chronic inflammatory bowel disease (IBD) that can affect the entire gastrointestinal tract (1). Although CD can develop at any age, many patients are diagnosed in childhood; specifically, $\sim 20 \%$ of patients with CD develop IBD before the age of 20 (2).

Malnutrition and impaired growth are the major complications of pediatric CD (1) and approximately one-third of CD children experience linear growth retardation (3). Abnormalities of linear growth during childhood probably lead to reduced adult stature in CD patients Indeed, up to $25 \%$ of CD patients do not reach their final target height (4). These complications, which may precede clinical evidence of $\mathrm{CD}$ by a few years, are more frequent in $\mathrm{CD}$ children compared to those with Ulcerative Colitis (UC), both at diagnosis and during follow-up $(5,6)$. Therefore, progressive 
growth failure is an important feature of disease severity and can be used to monitor the success of medical treatment and nutritional or surgical intervention (5). The causes of growth failure in these patients are complex and include the inflammatory process itself, malnutrition, malabsorption, and treatment with glucocorticoids. These factors act systemically as well as at growth plate level to inhibit bone growth.

The GH-IGF I axis is the major regulator of longitudinal bone growth: the systemic actions of the growth hormone $(\mathrm{GH})$ are mediated by IGF-I, which is produced by the liver. Furthermore, $\mathrm{GH}$ has been demonstrated to act, at the epiphyseal growth plate, either directly by stimulating resting/stem-like chondrocytes proliferation, or indirectly, through IGF-I, to promote chondrocyte hypertrophy (7). Levels of circulating IGF-I and its binding protein (IGFBP3) are good indicators of peripheral GH action, while decreased serum IGF-I and IGFBP3 levels are found in active CD (8).

Since the process of growth is supported by an adequate supply of nutrients, chronic malnutrition has long been implicated as a cause of poor growth in CD patients (9). Optimizing nutrition is thus an important step in managing growth failure, and the degree of intervention can be adjusted according to the severity of the condition. However, growth retardation can also occur under adequate nutritional conditions or even in absence of weight loss, indicating that other factors may be present (10). For example, an increase in cytokine production, induced by chronic inflammation, may affect growth, such as in infection and active systemic juvenile chronic arthritis (11-13). These inflammatory factors induce a state of $\mathrm{GH}$ resistance through different mechanisms: down-regulation of the growth hormone receptor (GHR), up-regulation of post receptor inhibitory proteins, reduced protein synthesis and/or increased protein degradation. Inflammatory cytokines have not only systemic actions but also direct local effects at the growth plate level; for example TNF- $\alpha$ and Interleukin-1 $\beta$ (IL-1 $\beta$ ) have been found to increase chondrocyte death (7). These mechanisms decrease circulating concentrations of IGF-I in CD patients despite normal GH secretion, resulting in linear growth failure (14). Finally, in CD patients, therapy with glucocorticoids (GCs) suppress the GH/IGF-I axis by inhibiting GH secretion (15) and downregulating the $\mathrm{GH}$ receptor in the liver, thereby inhibiting IGF-I secretion and activity (16). Furthermore, GCs inhibit chondrocyte proliferation, as well as increase their apoptosis (17). Thus, GCs may have positive effects in patients with chronic inflammation through their suppression of cytokine levels (18), but long-term GC therapy may lead to severe negative side effects such as osteoporosis and growth impairment.

To verify whether growth hormone receptor (GHR) gene expression plays a role in the growth failure of children with $\mathrm{CD}$, as a result of the chronic inflammatory condition and

Abbreviations: CD, Crohn's disease; GHBP, growth hormone binding protein; IGF-I, insulin-like growth factor-I; IBD, inflammatory bowel disease; UC, ulcerative colitis; GH, growth hormone; IGFBP3, IGF binding protein; TNF- $\alpha$, tumor necrosis factor $\alpha$; GHR, growth hormone receptor; IL-1 $\beta$, Interleukine$1 \beta$; GCs, glucocorticoids; PCDAI, Pediatric Crohn's Disease Activity Index; SOCS, suppressors of cytokine signaling; IL-6, Interleukine-6.
TABLE 1 | Inflammation and PCDAl values in CD patients at the time of diagnosis (t0) and at 1-year follow-up.

\begin{tabular}{llll}
\hline & CD T0 (min-max) & CD T1 (min-max) & Normal values \\
\hline CRP $(\mathrm{mg} \backslash \mathrm{dl})$ & $0.28-165.05$ & $<0.33-11.3$ & $<0.05$ \\
ESR $(\mathrm{mm} \backslash \mathrm{h})$ & $4-77$ & $1-40$ & $<20$ \\
PCDAl & $12.5-60$ & $0-22.5$ & $<10$ \\
\hline
\end{tabular}

malnutrition, we measured GH binding protein serum levels and GHR gene expression in lymphocytes from peripheral blood of patients with $\mathrm{CD}$ and from age-sex-matched controls. In CD patients, we analyzed the same parameters 1 year after onset of the disease and correlated them with anthropometric data and clinical activity, in order to discover whether these parameters may be influenced by therapy.

\section{PATIENTS}

In this multicenter study, 21 patients $(11$ males and 10 females) with a mean age of $12.1 \pm 0.9$ years were enrolled at the Bambino Gesù Children's Hospital in Rome and at the Pediatric Gastroenterology Division Unit of the University of Naples hospital. Subjects were consecutively recruited over 12 months and were evaluated prospectively for 1 year. Diagnosis of $\mathrm{CD}$ was based on clinical history, physical examination, radiologic studies, endoscopic appearance, and histological findings, according to the revised Porto criteria (19). Patients were classified, according to the Paris classification (20), as: 4 (A1,L2,B1); 1 (A1L1/L3B1); 5 (A1,L1,B1); 2 (A1L3/L4B1); 1 (A1b, L4a,B1); 2 (A1,L3B2); 4 (A1,L3,B1); 1 (A1, L2/L4, B1); 1 (A2,L1,B2).

Anthropometric measurements were taken by a professional nurse and recorded in the clinical diary, in accordance with World Health Organization guidelines. Stature was measured with a stadiometer in patients standing barefoot. Height was expressed according to chronological age, as a standard deviation score.

Patients had both elevated levels of both $\mathrm{C}$ reactive protein (CRP average: $31.69 \mathrm{mg} / \mathrm{dl}$, normal value: $<0.05 \mathrm{mg} / \mathrm{dl}$ ) and of erythrocyte sedimentation rate (ESR average: $35.33 \mathrm{~mm} / \mathrm{h}$, normal value $<20 \mathrm{~mm} / \mathrm{h}$ ) at disease onset. Range of CRP and ESR variations are showed in Table $\mathbf{1 .}$

The common presenting symptoms were abdominal pain $(6 / 21)$, diarrhea $(11 / 21)$, weight loss $(9 / 21)$, malnutrition $(5 / 21)$, rectorrhagia (5/21), and extraintestinal manifestations (10/21, including anemia $4 / 21$, oral ulcers $4 / 21$, and erythema nodosum $2 / 21$ ). Perianal lesions were present in $4 / 21$ patients (including anal skin tags $2 / 21$, perianal fissures $1 / 21$, and perianal fistulas $1 / 21)$.

Pediatric Crohn's Disease Activity Index (PCDAI) was determined according to Valletta et al. (21), with clinical remission defined as a PCDAI score of $<10$ and moderate/severe $\mathrm{CD}$ with a PCDAI of $>30$. At the time of diagnosis, 10 patients had a PCDAI $\geq 30$, revealing moderate/severe activity. Range of variation of PCDAI values is showed in Table $\mathbf{1}$. 
Blood was collected on the same day as the baseline clinical evaluation and after 1 year of therapy to measure IGF-I, GHBP and GH-R gene expression. Regarding therapy, at diagnosis patients were prescribed: mesalazine (Asalex, Chiesi Pharmaceuticals or Pentasa, Ferring; 50\%), azathioprine (Azatiioprina, Aspen Pharma or Azatioprina, Sandoz; 14\%), enteral nutrition (Modulen IBD, Nestlè; 50\%), oral steroids (Deltacortene, Bruno Pharmaceuticals; 50\%), nutritional treatment (Modulen IBD, Nestlè; 38\%), nine-month infliximab therapy (Emicade, MSD Italia; 1 patient) and 6-month adalimumab therapy (Humira, Abbvie srl; 1 patient).

At follow up, a decrease was found in both CRP and ESR ( $2.4 \mathrm{mg} / \mathrm{dl}$ and $9.5 \mathrm{~mm} / \mathrm{h}$, respectively). At this time, the average PCDAI score was 6.5 .

Twenty-seven healthy children, sex- and age-matched (mean age: $9.4 \pm 0.27$ years), were recruited as a control group at the Pediatric Auxology Unit of the Fondazione IRCCS Policlinico San Matteo Hospital. Their mean height was $-0.66 \pm 0.03$ SDS and their mean Body Mass Index (BMI) was $-0.8 \pm 0.19$ SDS (World Health Organization standards, 2006).

Written informed consent was obtained from parents or legal guardians of all children, and patients older than 13 signed a statement of assent. The study was approved by the Ethics Committee of the centers involved in the study.

\section{GHBP EVALUATION}

Serum levels of GHBP were measured by a commercially available ELISA (DSL-10-48100 ACTIVE hGHBP Elisa-Webster, Texas, USA). The minimum detectable concentration was 1.69 $\mathrm{pmol} / \mathrm{l}$. The intra- and inter-assay coefficients of variation were $5.59-4.78 \%$ and $8.36-5.11 \%$, with a quality control range of 20.25-198.24 pmol/l and 19.99-195.78 pmol/l, respectively.

\section{IGF-I DETERMINATION}

The serum IGF-I concentration was measured by an automatic assay that utilizes a solid-phase, enzyme-labeled chemiluminescent immunometric assay (Immulite 2000 IGF-IDPC, Los Angeles, CA and Immulite Analyzer). The intra-assay coefficients of variation were 3.9-2.4\%, with a quality control range of $77-1,358 \mathrm{ng} / \mathrm{ml}$. IGF-I values are expressed as mean a standard deviation score (SDS) according to Elmlinger et al. (22).

\section{GHR GENE EXPRESSION}

Peripheral blood mononuclear cells (PBMC) of patients and age-matched controls were separated by Ficoll density gradient centrifugation using a standard procedure (centrifugation at $1,800 \mathrm{rpm}$ for $30 \mathrm{~min}$ at room temperature, followed by the recovery of the PBMC ring at the interface).

For Real-Time GHR gene expression analysis, total RNA was isolated from PBMC using RNAeasy mini-columns (Qiagen, Hilden, Germany). RT-PCR was carried out with the SuperScript First-Strand Synthesis System. An RNA/primer mixture was prepared containing total RNA, oligo dT (50 ng/ $\mu \mathrm{l}), 10 \mathrm{mM}$
dNTP mix and DEPC water. The samples were incubated at for 5 mins and then on ice for at least $1 \mathrm{~min}$. A master reaction mixture, containing 10X RT buffer, $25 \mathrm{mM} \mathrm{MgCl}_{2}, 0.1 \mathrm{M}$ DTT, and RNAase OUT, was prepared for each sample. The reaction mixture was then added to the RNA/primer mixture, samples were mixed briefly and kept at room temperature for $2 \mathrm{~min}$. Fifty units of SuperScript II RT was added to each tube, the samples were mixed and incubated at for 10 mins, and the tubes were then incubated at for 50 mins, heat inactivated at for $15 \mathrm{mins}$, and chilled on ice. First strand cDNA was stored at $-20^{\circ} \mathrm{C}$ until use for real-time PCR. Quantitation of GHR mRNA expression was determined by quantitative real-time RT-PCR (Real-Time PCR 3500-Applied Biosystems) and assays on demand were used (Hs00174872_m1 Applied Biosystems). Normalization and validation of the data were carried out using glyceraldehyde-3phosphate dehydrogenase (GADPH) as a housekeeping control gene. Each GHR or GAPDH probe was labeled with a fluorescent reporter (FAM. Specifically, a 25 microliter volume reaction mixture containing $1.25 \mu \mathrm{l}$ Assay, $12.5 \mu$ l Master Mix, $10.25 \mu \mathrm{l}$ $\mathrm{H} 2 \mathrm{O}$, and $1 \mu \mathrm{l} \mathrm{cDNA}$ was treated under the following conditions: for $10 \mathrm{mins}$, for $15 \mathrm{~s}$, for $1 \mathrm{~min}$, for 40 cycles.

Quantitative Real-time PCR data were calculated by a standard curve and expressed as attograms $\mathrm{GHR} /\left(5 \times 10^{5}\right)$ attograms GAPDH. We chose the GAPDH gene because its expression shows reproducible and stable levels, moreover GAPDH CT are in the correct range for comparisons with the GHR gene. Furthermore, we evaluated possible variations in GAPDH expression values before considering them suitable for GHR gene expression data normalization and if necessary, disregarded the results.

The amplification efficiency of GHR with regard to GAPDH mRNA expression was evaluated by analyzing the $\Delta \mathrm{Ct}$ variation with template dilutions in the 1,000-fold range.

\section{STATISTICAL ANALYSIS}

Data are expressed as the mean \pm SEM. Statistical differences between patients before therapy and controls were determined using the Mann-Whitney U-test (Medcalc Software); whereas the non-parametric Wilcoxon test for paired samples was used to compare values in patients before and after 1 year of treatment. Correlations were analyzed using the Spearman's rank correlation test.

A value of $p<0.05$ was considered statistically significant.

\section{RESULTS}

At recruitment, $\mathrm{CD}$ children presented a mean height of -0.55 \pm 0.3 SDS (Figure 1A) and in two cases, the stature was below $-2 \mathrm{SD}$. Their BMI mean value was $-0.64 \pm 0.3$ SDS (Figure 1B).

At disease onset, significantly $(p=0.007)$ lower levels of IGFI were found in the CD group (mean value $-1.87 \pm 0.91$ SDS) compared to the control group (mean level $-0.28 \pm 0.14$ SDS; Figure 2A). GHBP was also significantly $(p<0.05)$ lower in patients compared to controls $(83.75 \pm 17.28 \mathrm{ng} / \mathrm{ml}$ and 153.95 $\pm 13.61 \mathrm{ng} / \mathrm{ml}$, respectively; Figure 2B). 


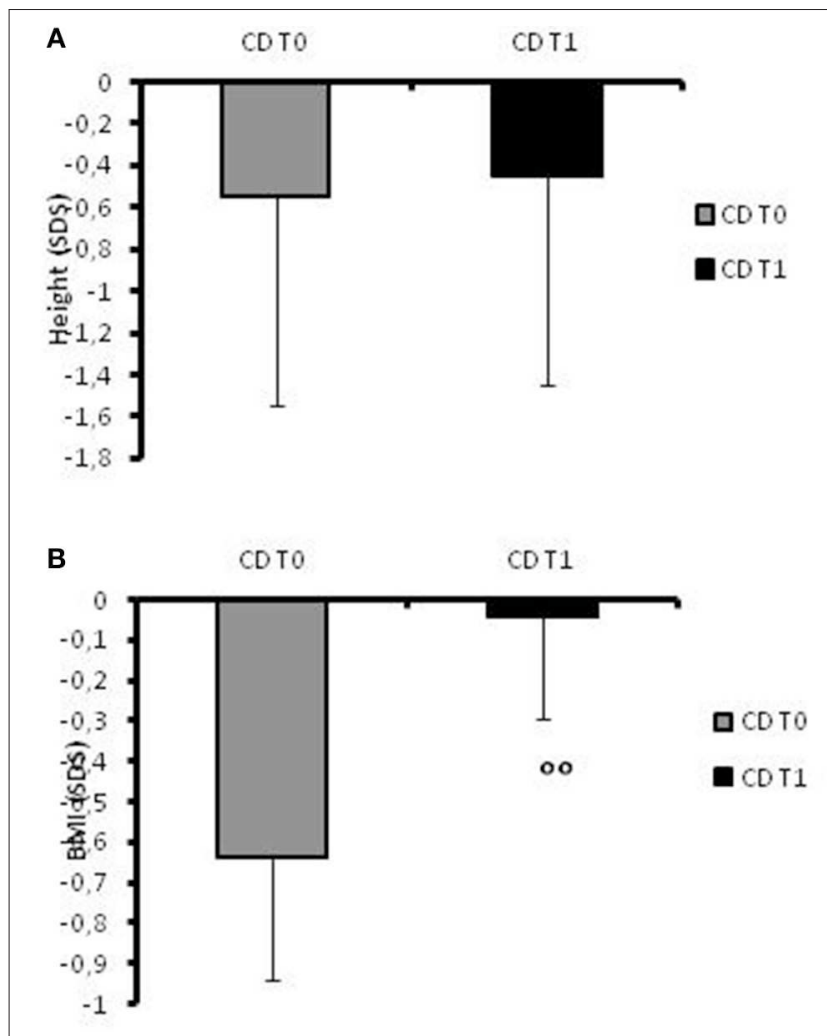

FIGURE 1 | (A)Height SDS values in CD patients at the time of diagnosis ( $\mathrm{t} 0$ ) and at 1-year follow-up. (B) BMI SDS values in CD patients at the time of diagnosis (t0) and at 1-year follow-up. o: $p=0.03 \mathrm{CD}$ children at t0 vs. CD children at $\mathrm{t} 1$.

Furthermore, GH-R mRNA expression was lower in patients at diagnosis (5201.59 $\left.\pm 2393.74 \mathrm{agGHR} / 5 \times 10^{5} \mathrm{agGAPDH}\right)$ compared to controls (9515.06 \pm 2605.68 agGHR/5 $\times$ $10^{5} \mathrm{agGAPDH}$ ) albeit not statistically significant (Figure 2C).

At follow-up, the mean height increased to -0.45 SDS (range -1.76 to +1.24 ; Figure 1A) and the patients' BMI SDS significantly $(p=0.03)$ increased after 12 months of therapy $(-0.045 \pm 0.25)$ compared to the onset of disease (Figure 1B). None of the patients had a stature lower than -2 SD at the 1-year follow-up.

However, the most important result was the significant ( $p=$ 0.033 ) increase in GHR mRNA expression in all patients at 1year follow-up (37572.17 $\left.\pm 22135.23 \mathrm{agGHR} / 5 \times 10^{5} \mathrm{agGAPDH}\right)$ in comparison with basal values (Figure 2C). Moreover, IGF-I levels had significantly $(p=0.039)$ improved in the year following diagnosis $(-0.051 \pm 0.2$ SDS $)$ compared to levels at disease onset (Figure 2A). On the contrary, GHBP values did not significantly change after 1 year of therapy $(98.18 \pm 19.62 \mathrm{ng} / \mathrm{ml})$ compared to basal levels (Figure 2B).

\section{DISCUSSION}

The inflammatory process in CD patients has been associated with the pathogenesis of growth delay through both IGF-I and GH-dependent mechanisms mediated by cytokines, although other factors such as innate genetic variations and inadequate caloric intake are implicated in $\mathrm{GH}$ resistance with consequent negative impact on linear growth (6). In CD patients, nutritional and pharmacological support, especially after the introduction of biological agents, decreases mucosal inflammation and alleviates symptoms, ameliorating linear growth and pubertal development. Indeed, the presence of lower levels of inflammatory cytokines in CD has been correlated with an increase in height growth velocity (7).

$\mathrm{GH}$ acts through the GHR, which is most commonly expressed in the liver, but also in the growth plate of long bones, in the intestinal epithelium and in all the layers of the gastrointestinal wall (23).

CD children show normal GH secretion in contrast with low circulating IGF-I levels, suggesting a significant degree of resistance to the effects of $\mathrm{GH}$ with consequent impaired linear growth. Hepatic GH resistance is induced by cytokines through two main mechanisms: down-regulation of GHR and upregulation of the members of the SOCS (suppressor of cytokine signaling) family. In particular, cytokines such as Interleukine6 (IL-6) increased SOCS3 expression, reducing STAT5b activity (24).

We wanted to verify whether GHR gene expression plays a role in the growth failure of children with $\mathrm{CD}$, as a result of the chronic inflammatory condition and malnutrition.

In our study, similar to previous reports, the IGF-I level was significantly lower in CD patients compared to controls, consistent with GH resistance (13). At 1-year follow up, the patients' IGF-I value had significantly increased, reaching higher levels compared to control values. Specifically, the IGF-I increase was significant and was concomitant with an overall improvement as assessed by physical examination of the patients. This probably reflects the reduced inflammation and the improvement of nutritional status during disease control. The BMI of our patients had also significantly increased after 1 year of therapy.

Cell surface amounts of GHR are the most important determinant of $\mathrm{GH}$ responsiveness (25). In our patients, GHR mRNA levels were lower at diagnosis consistent with an inflammatory state, although this result was not statistically significant. One year later, when the disease was under control, the GHR values were found to have significantly increased, together with the IGF-I levels. On the contrary, basal values of GHBP in CD patients were significantly lower compared to controls but they did not increase after 1 year of therapy. Therefore, our data show that GHBP level and GHR function are not closely correlated, as demonstrated also in other physiological and pathological conditions (26). GHR regulation and its cleavage to GHBP are tissue-specific. Therefore, it is possible that, in our patients, these mechanisms lead (27) to an increase in GHR availability on the cell's surface, thus improving GH action.

To the best of our knowledge, there are no previous studies reporting GHR gene expression values in CD children at onset of the disease and during follow-up. Our study raises the hypothesis of another cytokine interaction with the GH/IGF-I axis. This mechanism involves the GHR before the start of signal 


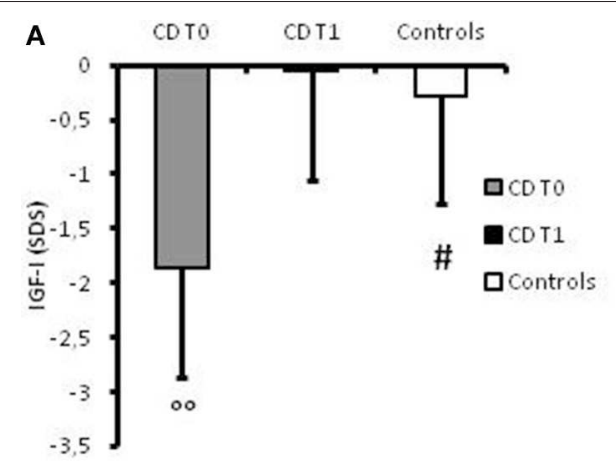

B
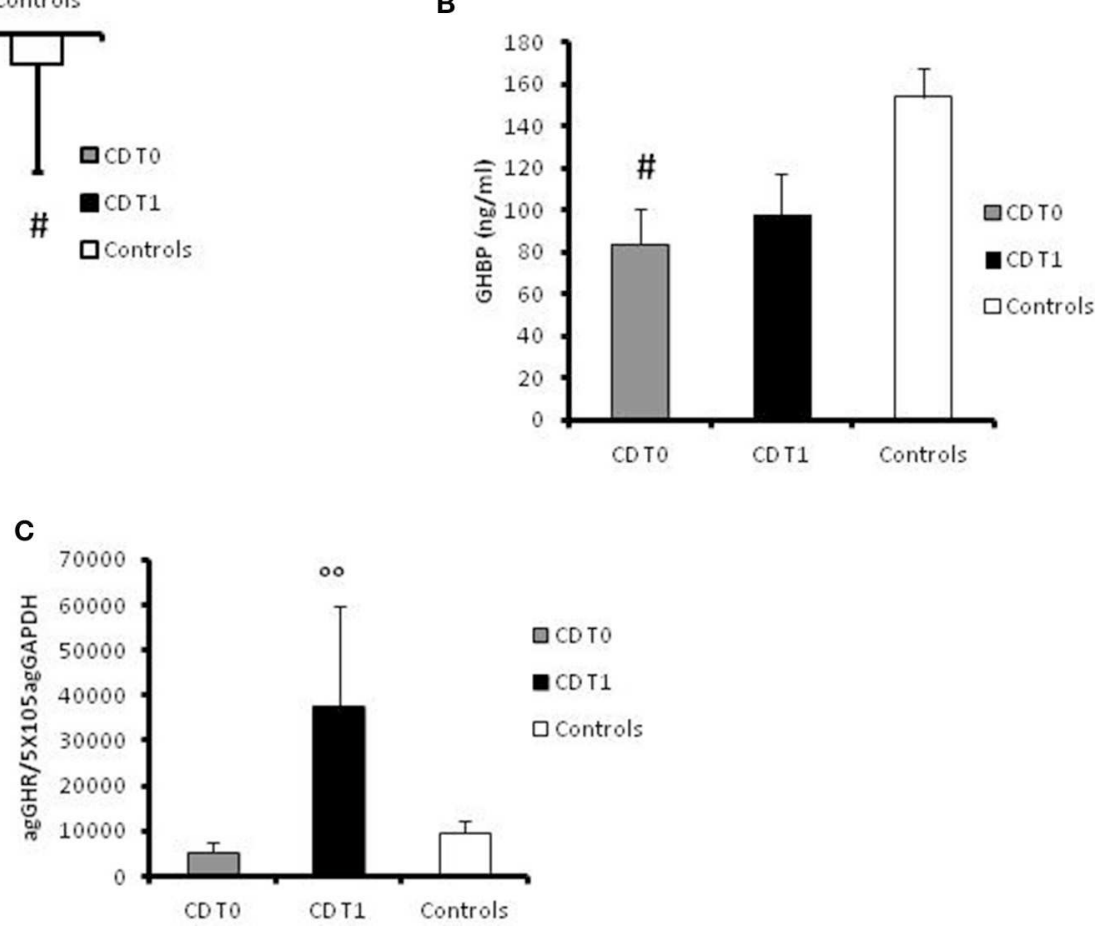

FIGURE 2 | (A) Serum values of IGF-I in controls, in CD patients at the time of diagnosis (t0) and at 1-year follow-up, expressed as ng/ml. \#: $p=0.007 \mathrm{CD}$ children vs. controls. $\circ: p<0.039 \mathrm{CD}$ children at to vs. CD children at t1. (B) Serum value of GHBP in controls, in CD patients at the time of diagnosis (to) and at 1-year follow-up, expressed as ng/ml. \#: $p<0.05 \mathrm{CD}$ children vs. controls. (C) GHR gene expression values in controls, in CD patients at the time of diagnosis (t0) and at 1-year follow-up, expressed as agGHR/5 $\times 10^{5} \mathrm{agGAPDH}$. o : $p=0.033 \mathrm{CD}$ children at to vs. CD children at $\mathrm{t} 1$.

transduction. Since GHR is present at growth plate level, it is possible of course that there is not only systemic but also local $\mathrm{GH} / \mathrm{IGF}-\mathrm{I}$ resistance.

However, in our study only two patients showed severe growth retardation at diagnosis with a height under -2 SDS (9.5\%) and this value is lower than the rate that has been previously reported (28). This is possibly due to the shorter interval between the onset of symptoms and diagnosis, due to improvements in diagnosis as shown also in the study of Song et al. (1). In our study, the median interval from onset of symptoms to diagnosis was 5.5 months, whereas the median diagnostic delay was 11.7 months in the previous study (29). Indeed, it has been shown that (30) the duration of developmental delays and height in CD patients are significantly correlated, suggesting that earlier diagnosis might minimize and prevent growth retardation by reducing the duration of symptoms before treatment, and so rectifying the growth inhibiting effects of malnutrition and inflammatory cytokines.

Our study has some limitations. Firstly, we acknowledge that the sample size was small, secondly the heterogeneity in drug treatments. Further studies with a larger sample size may provide more precise results.

Serum IGF and GHR gene expression levels change during the course of therapy, according to the clinical features, suggesting that disease activity modification is accompanied by variations in hypothalamic/pituitary-related factors. During disease remission, IGF-I and GHR mRNA expression increase, supporting the possibility of a strong correlation between growth factors, inflammatory process and nutritional status. These findings underline the importance of prompt control of inflammatory activity in order to prevent stunted growth and to promote good overall outcomes in mild to moderate CD. Furthermore, monitoring CD patients' growth is indispensable in order to assess their response to therapy over time (31).

\section{DATA AVAILABILITY}

The raw data supporting the conclusions of this manuscript will be made available by the authors, without undue reservation, on request of any qualified researcher.

\section{ETHICS STATEMENT}

Written informed consent was obtained from parents or legal guardians of all children, in accordance with the Declaration of Helsinki; patients older than 13 years signed a statement of assent. The study was approved by the Ethics Committee at both the Bambino Gesù Hospital and San Matteo Foundation Hospital.

\section{AUTHOR CONTRIBUTIONS}

$\mathrm{MB}$ and PD designed the study, revised the manuscript, and approved its final version. SP and CM performed experiments, 
collected, and analyzed data. SP and EB wrote the manuscript. CS, EM, and MM gave technical support and conceptual advice. All authors read and approved the final manuscript.

\section{ACKNOWLEDGMENTS}

The authors are grateful to Marialuisa Andreozzi for her contribution. The authors are grateful to Sheila Margaret

\section{REFERENCES}

1. Song SM, Kim Y, Oh SH, Kim KM. Nutritional status and growth in Korean children with Crohn's disease: a single-center study. Gut Liver (2014) 8:500-7. doi: $10.5009 /$ gnl13183

2. Kappelman MD, Moore KR, Allen JK, Cook SF. Recent trends in the prevalence of Crohn's disease and ulcerative colitis in a commercially insured US population. Dig Dis Sci. (2013) 58:519-25. doi: 10.1007/s10620-012-2371-5

3. Shamir R, Phillip M, Levine A. Growth retardation in pediatric Crohn's disease: pathogenesis and interventions. Inflamm Bowel Dis. (2007) 13:620-8. doi: 10.1002/ibd.20115

4. Sawczenko A, Ballinger AB, Savage MO, Sanderson IR. Clinical features affecting final adult height in patients with pediatric-onset Crohn's disease. Pediatrics (2006) 118:124-9. doi: 10.1542/peds.2005-2931

5. Newby E, Sawczenko A, Thomas A, Wilson D. Interventions for growth failure in childhood Crohn's disease. Cochrane Database Syst Rev. (2005) 3:3873. doi: 10.1002/14651858.CD003873.pub2

6. Ballinger A. Fundamental mechanisms of growth failure in inflammatory bowel disease. Horm Res. (2002) 58:7-10. doi: 10.1159/000064756

7. Sederquist B, Fernandez-Vojvodich P, Zaman F, Savendahl L. Impact of inflammatory cytokines on longitudinal bone growth. J Med Endocrinol. (2014) 53:T35-44. doi: 10.1530/JME-14-0006

8. Akobeng AI, Clayton PE, Miller V, Hall CM, Thomas AG. Low serum concentrations of insulin-like growth factor-I in children with active Crohn disease. effect of enteral nutritional support and glutamine supplementation. Scand J Gastroenterol. (2002) 37:1422-7. doi: 10.1080/003655202762671521

9. Belli DC, Seidman E, Bouthillier L, Weber AM, Roy CC, Pletincx $\mathrm{M}$, et al. Chronic intermittent elemental diet improves growth failure in children with Crohn's disease. Gastroenterology (1988) 94:603-10. doi: 10.1016/0016-5085(88)90230-2

10. Thomas AG, Taylor F, Miller V. Dietary intake and nutritional treatment in childhood Crohn's disease. J Pediatr Gastroenterol Nutr. (1993)17:75-81. doi: 10.1097/00005176-199307000-00011

11. MacRae VE, Wong SC, Farquharson C, Ahned SF. Cytokine actions in growth disorders associated with pediatric chronic inflammatory disease. Int J Mol Med. (2006) 18:1011-8. doi: 10.3892/ijmm.18.6.1011

12. De Benedetti F, Alonzi T, Moretta A, Lazzaro D, Costa P, Poli V, et al. Interleukin 6 causes growth impairment in transgenic mice through a decrease in insulin-like growth factor-1. a model for stunted growth in children with chronic inflammation. J Clin Invest. (1997) 99:643-50. doi: 10.1172/JCI119207

13. Bozzola E, Pagani S, Meazza C, Cortis E, Lisini D, Laarej K, et al. Changes in growth hormone receptor gene expression during therapy in children with juvenile idiopathic arthritis. Horm Res Paediatr. (2012) 77:52-8. doi: 10.1159/000334646

14. Ballinger AB, Camacho-Hubner C, Croft NM. Growth failure and intestinal inflammation. QJ Med. (2001) 94:121-5. doi: 10.1093/qjmed/94.3.121

15. Mushtaq T. The impact of corticosteroids on growth and bone health. Arch Dis Childhood (2002) 87:93-6. doi: 10.1136/adc.87.2.93

16. Kritsch KR, Murali S, Adamo MI, Ney DM. Dexamethasone decreases serum and liver IGF-I and maintains liver IGF-I mRNA in parenterally fed rats. Am J Physiol. (2002) 282:R528-36. doi: 10.1152/ajpregu.00085.2001

17. Chrysis D, Nilsson O, Ritzen EM, Savendahl L. Apoptosis is developmentally regulated in rat growth plate. Endocrine (2002) 18:271-8. doi: 10.1385/ENDO:18:3:271

18. Marcovecchio ML, Mohn A, Chiarelli F. Inflammatory cytokines and growth in childhood. Curr Opin Endocrinol Diabetes Obesity (2012) 19:57-62. doi: 10.1097/MED.0b013e32834ed61f
McVeigh for the English revision of the paper. The Onlus II bambino e ii suo pediatra via XX Settembre n.28 28066 Galliate (Novara) supported the realization of this paper. The authors would like to thank the staff of the Adolfo Ferrata Medical Library at the University of Pavia (Italy) for their invaluable assistance. The Onlus II bambino e ii suo pediatra financied the language revision of the manuscript.

19. Levine A, Koletzko S, Turner D, Escher JC, Cucchiara S, de Ridder L, et al. ESPGHAN revised porto criteria for the diagnosis of inflammatory bowel disease in children and adolescents. J Pediatr Gastroenterol Nutr. (2014) 58:795-806. doi: 10.1097/MPG.0000000000000239

20. Levine A, Griffiths A, Markowitz J, Wilson DC, Turner D, Russell RK, et al. Pediatric modification of the Montreal classification for inflammatory bowel disease: the Parisclassification. Inflamm Bowel Dis. (2011) 17:1314-21. doi: 10.1002/ibd.21493

21. Valletta E, Fornaro M. Malattie infiammatorie croniche intestinali. Quaderni acp. (2013) 20:3-15.

22. Elmlinger MW, Kuhnel W, Weber MM, Ranke MB. Reference ranges for two automated chemiluminescent assays for serum insulin-like growth factor I (IGF-I) and IGFbinding protein 3 (IGFBP-3). Clin Chem Lab Med. (2004) 42:654-64. doi: 10.1515/CCLM.2004.112

23. Denson LA, Menon RK, Shaufl A, Bajwa HS, Williams CR, Karpen SJ. TNF- $\alpha$ downregulates murine hepatic growth hormone receptor expression by inhibiting Sp1 and Sp3 binding. J Clin Invest. (2001) 107:1451-8. doi: 10.1172/JCI10994

24. Zhao Y, Xiao X, Frank SJ, Lin HY, Xia Y. Distinct mechanisms of induction of hepatic growth hormone resistance by endogenous IL6, TNF- $\alpha$, IL-1 $\beta$. Am J Physiol Endocrinol Metab. (2014) 307:E186-98. doi: 10.1152/ajpendo.00652.2013

25. Delehaye-Zervas M C, Mertani H, Martini J F, Nihoul-Feketé C, Morel G, Postel-Vinay MC. Expression of the growth hormone receptor gene in human digestive tissue. JCI (1994) 78:1473-80. doi: 10.1210/jcem.78.6. 8200952

26. Kissmeyer-Nielsen P, Christensen H, Laurberg S. Trophic effects of biosynthetic growth hormone on normal and defunctioned left colon in rats. Scand J Gastroenterol. (1995) 30:246-51. doi: 10.3109/00365529509 093272

27. Flores-Morales A, Greenhalgh CJ, Norstedt G, Rico-Bautista E. Negative regulation of growth hormone receptor signalling. Mol Endocrinol. (2006) 20:241-53. doi: 10.1210/me.2005-0170

28. Gasparetto M, Guariso G. Crohn's disease and growth deficiency in children and adolescents. World J Gastroenterol. (2014) 20:13219-2840. doi: 10.3748/wjg.v20.i37.13219

29. Amit T, Moussa Youdim BH, Hochberg Z. Does serum growth hormone binding protein reflect human GHreceptor function? JCEM (2000) 85:927-32.

30. Bresson JL, Jeay S, Gagnerault MC, Kayser C, Beressi N, Wu Z, et al. Growth hormone $(\mathrm{GH})$ and prolactin receptors in human peripheral blood mononuclear cells: relation with age and GH-binding protein. Endocrinology (1999) 140:3203-9. doi: 10.1210/endo.140.7.6854

31. Walters TD, Griffiths AM. Growth impairment in pediatric inflammatory bowel disease. In Mamula P, Markowitz JE, Baldassano RN editors. Pediatric Inflammatory Bowel Disease New York, NY: Springer (2008). p. 103-4.

Conflict of Interest Statement: The authors declare that the research was conducted in the absence of any commercial or financial relationships that could be construed as a potential conflict of interest.

Copyright (C) 2018 Pagani, Bozzola, Strisciuglio, Meazza, Miele, Malamisura, De Angelis and Bozzola. This is an open-access article distributed under the terms of the Creative Commons Attribution License (CC BY). The use, distribution or reproduction in other forums is permitted, provided the original author(s) and the copyright owner(s) are credited and that the original publication in this journal is cited, in accordance with accepted academic practice. No use, distribution or reproduction is permitted which does not comply with these terms. 